\title{
Knowledge, Attitudes and Preventive Practices on Ebola Virus Disease in the Kintampo Districts of Ghana
}

\author{
Obed Ernest A. Nettey1, Yeetey A. Enuameh"1, Charles Zandoh'1, Edward Apraku Anane1, \\ Mahama Abukari'1, Francis Agbokey¹, Awurabena Q. Dadzie', Mathilda Tivura1, \\ Dennis Adu-Gyasi', Lawrence Gyabaa Febir'1, Kenneth A. Ae-Ngibise1, Timothy Letsa², \\ Kwaku Poku Asante1, Seth Owusu-Agyei ${ }^{1}$
}

${ }^{1}$ Kintampo Health Research Centre, Kintampo, Ghana

${ }^{2}$ Regional Health Directorate, Ghana Health Service, Sunyani, Ghana

Email: ernest.nettey@kintampo-hrc.org

How to cite this paper: Nettey, O.E.A., Enuameh, Y.A., Zandoh, C., Anane, E.A., Abukari, M., Agbokey, F., Dadzie, A.Q., Tivura, M., Adu-Gyasi, D., Febir, L.G., Ae-Ngibise, K.A., Letsa, T., Asante, K.P. and Owusu-Agyei, S. (2016) Knowledge, Attitudes and Preventive Practices on Ebola Virus Disease in the Kintampo Districts of Ghana. Health, 8, 1465-1484. http://dx.doi.org/10.4236/health.2016.814146

Received: September 7, 2016

Accepted: November 11, 2016

Published: November 14, 2016

Copyright $\odot 2016$ by authors and Scientific Research Publishing Inc. This work is licensed under the Creative Commons Attribution International License (CC BY 4.0).

http://creativecommons.org/licenses/by/4.0/ (c) (i) Open Access

\begin{abstract}
This study describes community members' knowledge of Ebola Virus Disease (EVD), their attitudes and preventive practices. A mixed methods approach was used. A random sample of 1028 community members aged 15 - 65 years was interviewed in a quantitative survey. This was complemented with a qualitative study involving 24 opinion leaders who were carefully selected. The study was conducted in Kintampo North and South districts of Ghana from August 2014 to October 2014. 83\% of respondents had heard of EVD, but $62.5 \%$ did not know the duration between the time of infection and onset of clinical symptoms. The most popular symptom mentioned spontaneously was bleeding through body orifices (48.6\%). Majority of respondents mentioned handshake or skin contact as a mode of transmission (57.3\%) and reduced contact with bats as a means to prevent the spread of EVD (58.1\%). Knowledge of transmission of body fluids such as faeces, blood or urine was low $(<10 \%)$, though this varied significantly by socio-demographic group. Majority (94\%) of respondents acknowledged that EVD was a serious disease, however, only 58\% saw themselves at risk. Current preventive behaviours included: improved hand hygiene (83\%) and avoidance of handshakes and physical contact with people (81\%). Community members in the Kintampo districts have high level of awareness of EVD, but important gaps in knowledge of EVD still exist, especially concerning body fluids as a mode of transmission. There is the need to intensify educational messages as part of Ghana's preparedness towards a potential EVD outbreak.
\end{abstract}

\section{Keywords}

Ebola, Virus, Kintampo, Ghana, Knowledge, Attitudes, Preventive Practices, KAP 


\section{Introduction}

The recent Ebola Virus Disease (EVD) outbreak in West Africa has been the worst since it was first reported in 1976. By March 27th 2016, 28,646 cases and 11,323 deaths were reported, mostly in Guinea, Sierra Leone and Liberia [1]. The WHO has since declared the end of the Public Health Emergency of International Concern regarding the Ebola virus disease outbreak in West Africa. However, there are sporadic cases reported [1]. The EVD outbreak had devastating consequences aside illnesses and deaths; it adversely affected health systems [2] [3] [4] [5], livelihoods, economies [6], and long-held cultural traditions [7]. At the height of the outbreak, widespread poverty, corruption, underdeveloped health care systems, low educational attainment [2] [4] and cultural practices [8] were identified as exacerbating its effects.

Though not directly affected by EVD, its close proximity to affected countries put Ghana at high risk of an outbreak [5]. Ghana had a high probability of experiencing EVD cases [5]. In July 2014 when the first EVD case was reported in Nigeria, Ghana's capital town, Accra, was overwhelmed with its worst Cholera outbreak in recent times. This heightened the poor emergency preparedness of Ghana's health system to manage a possible EVD outbreak.

Media messages during this period emphasized reduction in bushmeat consumption, body contact and handshakes as well as contact with pigs as prevention strategies, in agreement with WHO guidelines [9]. Also, they mentioned that EVD had no cure. In the absence of a cure, therefore, behaviour change was the most realistic option for preventing and controlling the epidemic [8]. Such behaviour change required interventions based on an understanding of peoples' knowledge, beliefs, attitudes and behavioural patterns.

This study therefore sought to describe community members' knowledge of EVD, their attitudes and practices (behaviour) related to the disease at household level. This was to identify potential knowledge gaps to address during community education for prevention of the disease. This study is in response to increased local concerns for EVD at the height of the outbreak. It is also an important contribution by Kintampo Health Research Centre (KHRC) whose mandate is to carry out relevant public health research to enhance the health of communities in the middle belt of Ghana [10] [11].

\section{Methods}

A community-based cross-sectional study was conducted from 18th August to 17th October 2014, using both quantitative and qualitative data collection methods.

\subsection{Study Area}

The study was conducted in the Kintampo Districts of Ghana, where the Kintampo Health and Demographic Surveillance System (KHDSS) operates. The KHDSS is run by the Kintampo Health Research Centre (KHRC) [10] [11]. The resident population of 134,970 individuals lives in largely rural communities with about half of the population having no formal education [10]. Majority of residents are farmers and mainly belong 
to the Christian religion. Other population characteristics of the study area have been described in a paper by Owusu-Agyei et al. The districts have 2 hospitals, 6 health centres, 2 rural clinics and 53 functional Community-based Health Planning and Services (CHPS) zones. Community health officers (CHOs) provide health education at community durbars, radio discussions and during home visits.

\subsection{Data Collection Procedures}

\subsubsection{Quantitative Methods}

A close-ended pretested questionnaire was administered to a random sample of 1028 individuals of both sexes by trained interviewers who read questions out loud. Each questionnaire consisted of 3 sections assessing the knowledge, attitudes and preventive practices of EVD. Responses to interviewers' questions were spontaneous followed by prompts. Based on local media broadcasts and WHO guidelines [9] at the time, EVD transmission by handshakes or skin contact, monkeys, and other bushmeat was classified as correct responses ${ }^{1}$.

The knowledge section inquired about awareness of EVD, information sources about EVD, signs and symptoms of EVD, knowledge about EVD transmission modes and prevention. In the attitude section, respondents answered "Agree", "Not Sure" or "Disagree" to 10 attitude statements. The practices section elicited responses on the first thing respondent would do on suspicion of someone having EVD symptoms, and their current practices to avoid EVD.

\subsubsection{Qualitative Methods}

In depth interviews (IDIs) were conducted by trained interviewers using pretested interview guides in English or the local language (Twi). The guide explored knowledge, attitudes and perceptions on EVD. IDIs were audio-recorded and transcribed verbatim. The interviews were conducted at homes or workplaces of the participants and lasted about thirty (30) minutes each. Data collection continued until saturation was reached. Interviews conducted in the local language (Twi) were first translated and then transcribed verbatim into English language. As a quality control check, the audio recorded transcriptions were exchanged between transcribers and vetted to make sure the typed transcripts matched the audio transcripts.

\subsubsection{Sample Size and Sampling}

For the survey, a sample size of 1028 was computed based on $90 \%$ power (alpha $=0.05$ ) to determine if $22 \%$ of residents of the Kintampo districts knew of EVD, comparable to the $18 \%$ in a study in Cote d'Ivoire [12]. A two-stage sampling approach was used: first, 1,028 out of 30,155 households in the study area, after which one individual of working age 15 to 65 years was selected from each household. This sampling process was used because the population of interest were households. The work-age population was sampled because they are the breadwinners in their household and their knowledge, attitudes and behaviour tends to affect the general health status of the household. Sampling ${ }^{1}$ The questionnaires and interview guide are available from KHRC upon request. 
was done using STATA 12 [13] on KHDSS databases which has a record of all households and members in situations where a respondent was unavailable for interview, a replacement was made from a supplementary sample drawn of other eligible respondents residing in the same household or others within the same geographic cluster.

IDIs were conducted among another 24 community members involving 3 Unit Committee members, 2 Assemblymen, 1 chief, 6 religious leaders and 12 community members. The respondents were selected as representative sample of different types of social hierarchy in the study area.

\subsubsection{Data Management and Analysis}

Quantitative data were double-entered into Microsoft FoxPro 9.0, cleaned and verified. This data were imported into STATA 12 [13] as the final dataset for analysis. Findings of the survey were presented as proportions (i.e. frequencies and graphs). To determine levels of knowledge, index scores were computed for symptoms, modes of transmission and prevention of EVD based on the number of accurate responses given. Respondents were grouped by tertiles of scores obtained, based on their level of knowledge i.e. low, medium or high.

To compute knowledge tertiles, responses to knowledge questions were weighted: spontaneous correct responses were scored 2 points, prompted correct responses 1 point and wrong responses 0 points. Weighted scores were then summed up for each respondent and categorized into three quantiles using STATA 12 [13]. Tertiles were tabulated by respondents' socio-demographic characteristics: sex, age, education, occupation, place of residence, municipality/district and household wealth quintile. Relationships between outcomes were determined using Pearson's chi-square test at $5 \%$ significance.

Household wealth quintiles were constructed using principal components analysis (PCA) based on aggregates of previously weighted household assets such as animals (e.g. livestock, poultry etc), consumer items (e.g. televisions, radios, mobile phones, cars etc) and dwelling characteristics (e.g. floor materials, water source, toilet facilities etc) for all KHDSS households. Quintiles were categorized from lowest (Most Poor) to highest (Least Poor).

Qualitative data was managed using NVIVO 8 software. Interview transcripts were imported into NVIVO 8 for coding and subsequent analysis. To ensure inter-coder reliability and agreement, coding was done by two researchers. Inter-coder agreement was always above $90 \%$.

\subsubsection{Ethical Considerations}

The study was approved by Kintampo Health Research Centre Institutional Ethics Committee. Respondents aged 18 years or more gave oral consent to participate in the EVD survey, whilst those less than 18 years gave their assent in addition to their parent/guardian consenting. Data was kept confidential by storage at the secured data bank in KHRC. For IDIs, each participant was consented by signing or thumb-printed a consent sheet. A witness was required in the case of those unable to read. 


\section{Results}

\subsection{Demographic Characteristics of Survey Respondents}

A total of 1,028 respondents (405 males and 623 females) were interviewed. As shown in Table 1, the mean age of respondents was 37.1 years. The largest and smallest agegroups were persons aged 30 - 39 (26.5\%) and 15 - 19 years (11\%) respectively.

Majority of respondents either had no education $(37.8 \%)$ or had attained only middle/Junior High School (32.7\%); only 11.4\% of the respondents had attained secondary or higher education. Most respondents were farmers, labourers or domestics (56.3\%). $15 \%$ were unemployed and $49.7 \%$ resided in large rural communities (i.e. with population between 1000 and 4999) (Table 1(a)).

$16.5 \%$ of males have secondary or higher education compared to $8 \%$ of females (Table 1(a)). 20 - 29 year-olds had the largest percentage of secondary or higher education (Table 1(a)).

Majority of older age-groups (40 years+) were mostly in farmer-labourer-domestic occupations compared to younger age-groups, who were typically self-employed traders or not working.

Also, there was a larger percentage of female respondents in urban locations, in Kintampo North Municipality and in the least poor quintile compared to men. 20 - 29 year-old had the largest percentage in terms of residence in urban locations or in Kintampo North Municipality (Table 1(a)).

For the qualitative interviews, 6 communities were purposively selected among the communities where the quantitative data was collected: 3 in Kintampo North and 3 in Kintampo South. Communities were selected based on their population size, religious and ethnic diversity. Community members and Opinion leaders were also purposively selected based on how influential they are and their level of interaction with other community members. Community members and opinion leaders who were more influential and had the opportunity to interact with more people in a day were selected for the interview. Twenty-four IDIs were conducted among 13 males and 11 females. Majority of interviewees were over 40 years old. Half had no formal education (Table 1(b)).

Majority were farmers except a few who were engaged in small scale trading activities, such as brewing of alcoholic drinks, food vending, sewing/dressmaking and chemical selling.

\subsection{Respondents' Awareness of Basic EVD Facts}

From the survey, 83\% (852/1028) of respondents had heard of EVD. Of these, 54.2\% (458/852) mentioned that EVD has no cure, 25.7\% (217/852) thought EVD has a cure, whilst $20.1 \%$ (170/852) were unaware of a cure. $62.5 \%$ (532/852) did not know the duration between the time of infection and onset of clinical symptoms.

\subsection{Where Respondents Heard about EVD}

The survey showed that majority $93.9 \%(800 / 852)$ of respondents heard of EVD from 
Table 1. (a) Demographic characteristics of survey respondents; (b) Demographic characteristics of IDI participants.

(a)

\begin{tabular}{|c|c|c|c|c|c|c|c|c|}
\hline \multirow{2}{*}{ Variable } & \multicolumn{2}{|c|}{ Sex } & \multicolumn{5}{|c|}{ Age } & \multirow{2}{*}{ Total } \\
\hline & Male & Female & $<20$ & $20-29$ & $30-39$ & $40-49$ & $50+$ & \\
\hline \multicolumn{9}{|c|}{ Education } \\
\hline Primary & $54(13.3)$ & $132(21.2)$ & $39(34.5)$ & $38(16.8)$ & $48 \quad(17.6)$ & $29(13.7)$ & $32(15.6)$ & $186(18.1)$ \\
\hline Middle/JSS & $142(35.1)$ & $194(31.1)$ & $49(43.4)$ & $88(38.9)$ & $99(36.4)$ & $58(27.4)$ & $42(20.5)$ & $336(32.7)$ \\
\hline Secondary & $67(16.5)$ & $50(8.0)$ & $11(9.7)$ & $50(22.1)$ & $25(9.2)$ & $21(9.9)$ & $10(4.9)$ & $117(11.4)$ \\
\hline Farmer, Labourer, Domestic & $255(63.0)$ & $324(52.0)$ & $28(24.8)$ & $84(37.2)$ & $170(62.5)$ & $141(66.5)$ & $156(76.1)$ & $579 \quad(56.3)$ \\
\hline Self-Employed, Trader & $27(6.7)$ & $130(20.9)$ & $7(6.2)$ & $36(15.9)$ & $50(18.4)$ & $43(20.3)$ & $21(10.2)$ & $157(15.3)$ \\
\hline Other-Employed Trader & $16(4.0)$ & $28(4.5)$ & $3(2.7)$ & $18(8.0)$ & $15(5.5)$ & $8(3.8)$ & $0(0.0)$ & $44(4.3)$ \\
\hline Other & $43(10.6)$ & $50(8.0)$ & $32(28.3)$ & $23(10.2)$ & $17(6.3)$ & $12(5.7)$ & $9(4.4)$ & $93(9.0)$ \\
\hline \multicolumn{9}{|c|}{ Place of residence } \\
\hline North & $199(49.1)$ & $365(58.6)$ & $57(50.4)$ & $141(62.4)$ & $146(53.7)$ & $108(50.9)$ & $112(54.6)$ & $564(54.9)$ \\
\hline South & $206(50.9)$ & $258(41.4)$ & $56(49.6)$ & $85(37.6)$ & $126(46.3)$ & $104(49.1)$ & $93(45.4)$ & $464(45.1)$ \\
\hline \multicolumn{9}{|c|}{ Household Wealth Quintile } \\
\hline Most Poor & $46 \quad(13.5)$ & $56(10.9)$ & $10 \quad(8.8)$ & $35(15.5)$ & $44(16.2)$ & $30(14.2)$ & $38 \quad(18.5)$ & $157(15.3)$ \\
\hline More Poor & $65(19.1)$ & $78(15.2)$ & $22(19.5)$ & $38(16.8)$ & $57(21.0)$ & $33(15.6)$ & $40(19.5)$ & $190(18.5)$ \\
\hline Poor & $74(21.8)$ & $92(18.0)$ & $22(19.5)$ & $38(16.8)$ & $49(18.0)$ & $40(18.9)$ & $50(24.4)$ & $199(19.4)$ \\
\hline Less Poor & $80(23.5)$ & $141(27.5)$ & $30(26.5)$ & $64(28.3)$ & $56(20.6)$ & $54(25.5)$ & $38(18.5)$ & $242(23.5)$ \\
\hline Least Poor & $75(22.1)$ & $145(28.3)$ & $29(25.7)$ & $51(22.6)$ & $66(24.3)$ & $55(25.9)$ & $39(19.0)$ & $240(23.3)$ \\
\hline Total & 405 (39.4) & $623(60.6)$ & $113(11.0)$ & $226(22.0)$ & $272(26.5)$ & $212(20.6)$ & 205 (19.9) & $1028(100.0)$ \\
\hline
\end{tabular}


(b)

\section{Characteristic}

\section{$\%$}

Sex

Male

Female

Age

$20-39$

$40+$

\section{Education}

No Education

Primary

Middle/JHS

Secondary+

\section{Occupation}

Farmer

Other(Services)

- TBA $(\mathrm{n}=1)$

- Food Vendor $(\mathrm{n}=1)$

- Chemical Seller $(\mathrm{n}=1)$

- Pito (alcohol) brewery $(\mathrm{n}=1)$

- Seamstress $(\mathrm{n}=1)$

Place of residence

Rural

Urban

Municipality/District

Kintampo North Municipality

Kintampo South District

\section{$n$}

13

11

5

19

12

9

1

2

19

24

0

12

12

24
54.2

45.8

20.8

79.2

50.0

37.5

4.2

8.3

79.2

20.8

100.0

0.0

50.0

50.0

100.0

radio presentations. Others $61.9 \%$ (526/852) heard of the disease from friends and relations and 49.9\% (425/852) from television discussions. Other important sources of information were places of worship such as churches, mosques and shrines 30\% (261/ 852). Community information centres, health outreaches, the Internet, newspapers and mobile vans were less common sources, each less than $15 \%$.

\subsection{Knowledge of EVD Signs and Symptoms}

The most popular spontaneous response for signs and symptoms of EVD was bleeding through body orifices $48.6 \%$ (414/852). Other signs and symptoms such as reduced urine, difficulty in breathing and chest pain were less known by respondents (Figure 1). 


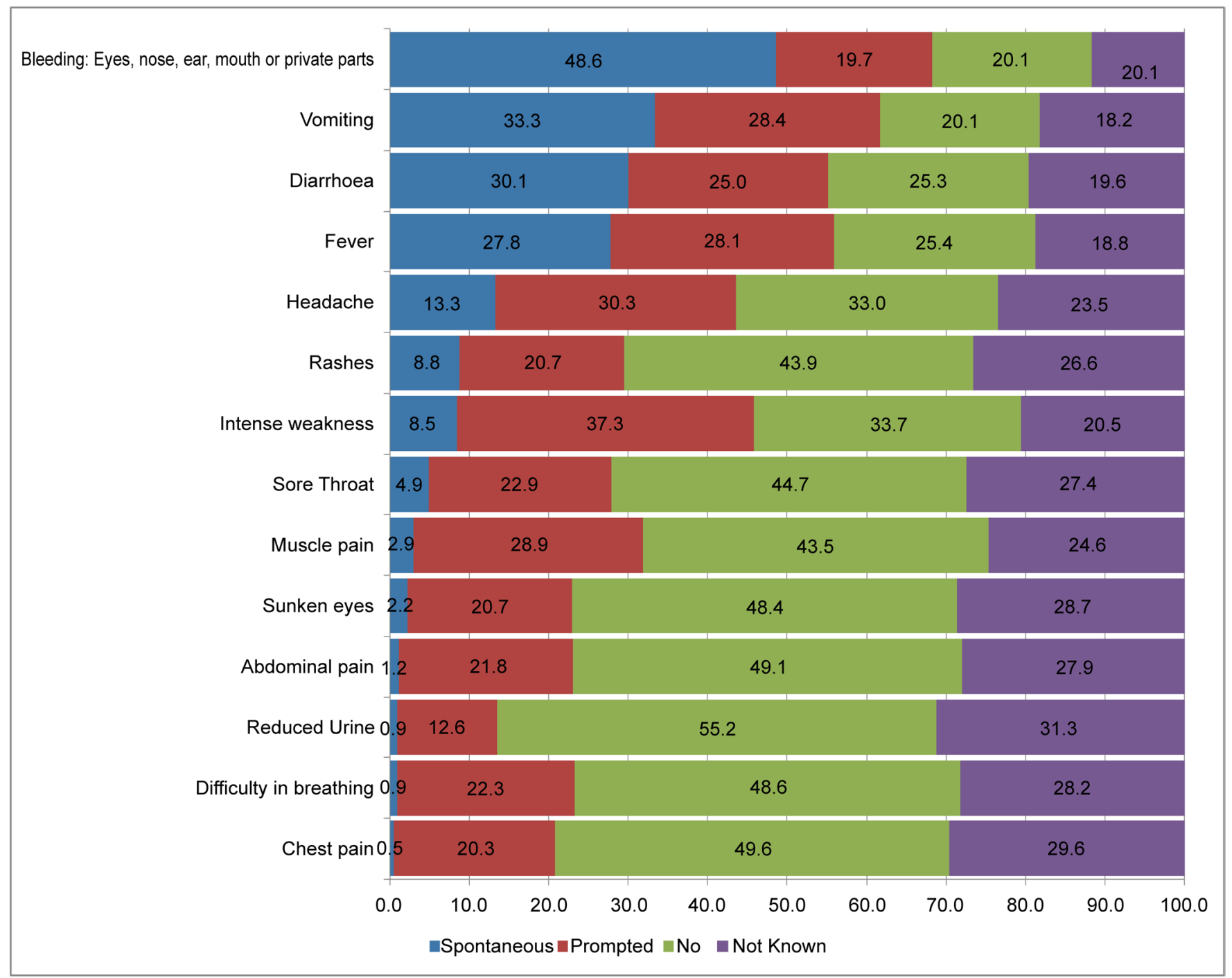

Figure 1. Knowledge of signs and symptoms of EVD.

More than half of respondents were unaware of signs and symptoms such as headache, rashes, intense weakness, sore throat, muscle pain, sunken eyes, abdominal pain, reduced urine, difficulty in breathing or chest pain being associated with EVD (Figure $1)$.

\subsection{Knowledge of How EVD Is Transmitted}

Majority $(57.3 \%$; 488/852) of respondents spontaneously mentioned handshake or skin contact as a mode of transmission for EVD. Less than $10 \%$ of study participants spontaneously responded that EVD is transmitted through other body fluids such as faeces, blood or urine (Figure 2). Even after prompting, 68\% (579/852), 51.9\% (442/852), 61\% (520/852), 49.8\% (424/852), 43.8\% (373/852), 47.8\% (407/852) and 45\% (383/852) said "No" or "Don't Know" to urine, blood, faeces, saliva, kissing, sweat and semen respectively as modes of EVD transmission (Figure 2). 


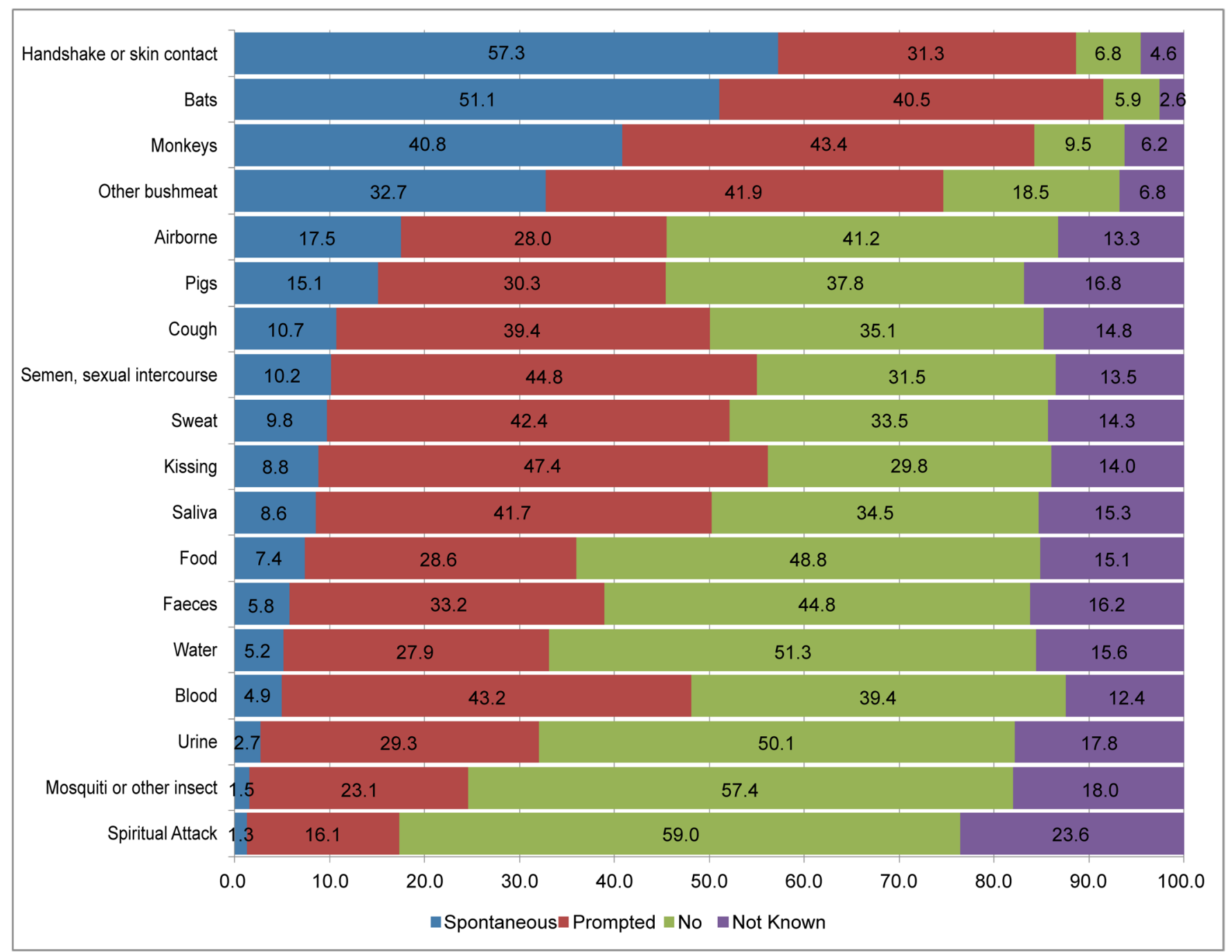

Figure 2. Knowledge of how EVD is transmitted.

\subsection{Knowledge of How to Prevent EVD}

As high as 58.1\% (495/852) of respondents spontaneously mentioned reduced contact with bats, monkeys, pigs and other wild animals as a means to preventing EVD spread (Figure 3).

As shown in Figure 3, maintenance of hand hygiene (i.e. proper hand-washing and the use of hand sanitizers) was the next most commonly perceived prevention approach as $36.5 \%$ (311/852) mentioned spontaneously. Culling of infected animals and burning their carcasses was least mentioned spontaneously as a means of prevention $8 \%$ (71/ 852).

Tables 2-4 present associations of respondent characteristics by tertiles of the population. With the exception of sex and age, differences across the tertiles of other socio-demographic characteristics-education, place of residence and household wealth quintiles-were highly significant for knowledge of EVD symptoms (Table 2), modes of transmission (Table 3 ) or preventive practices (Table 4). 


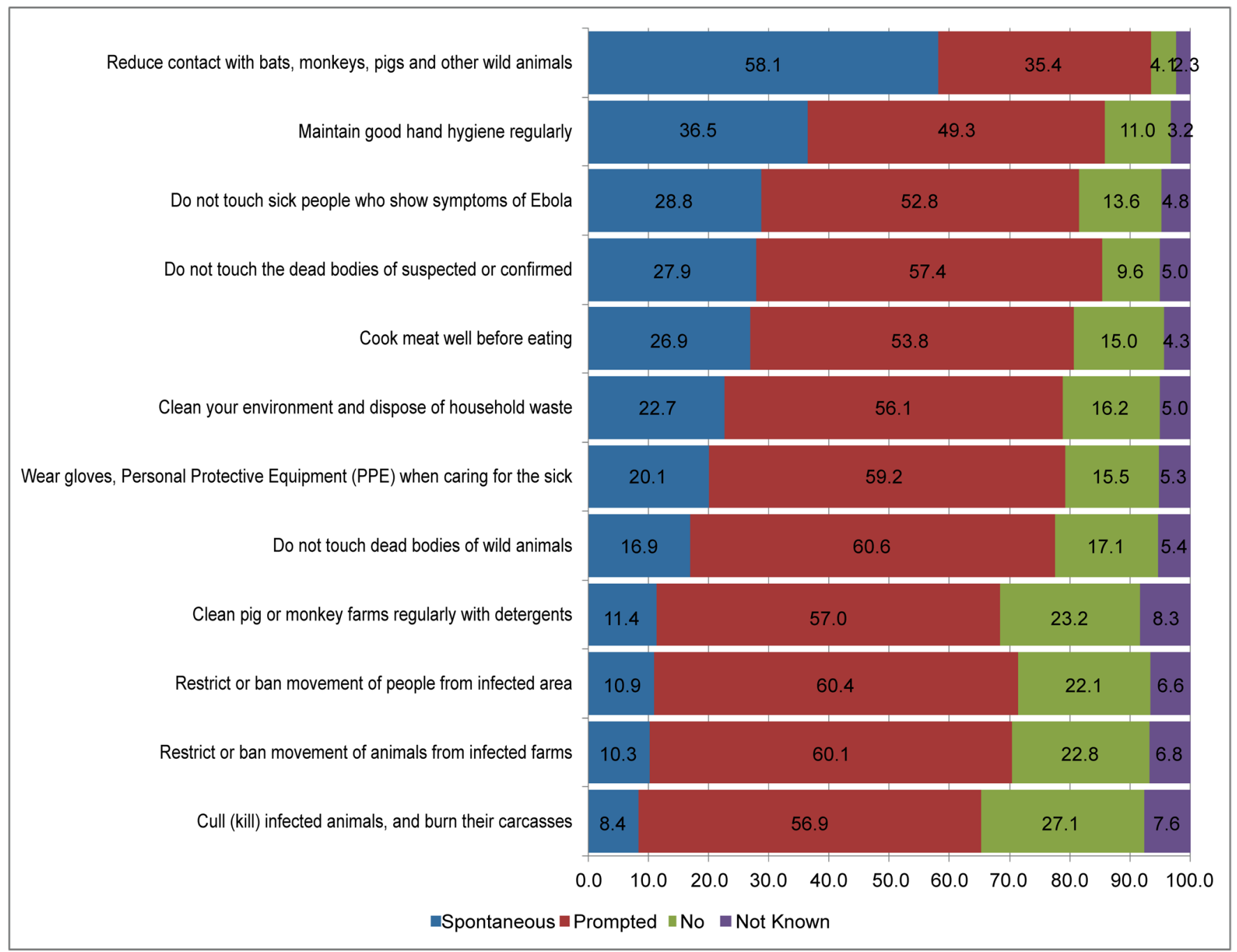

Figure 3. Knowledge of how to prevent EVD.

Levels of knowledge of EVD symptoms were highest among respondents with secondary or higher education, in professional, clerical occupations, living in urban locations, living in Kintampo North Municipality and those in the least poor wealth quintile (Table 2).

Similarly, persons with secondary or higher education, in professional, clerical occupations, living in urban locations, living in Kintampo North Municipality and those in the least poor wealth quintile were much more knowledgeable about modes of EVD transmission (Table 3). These same categories of respondents knew more about EVD preventive practices (Table 4). In contrast with knowledge of EVD symptoms and modes of transmission, however, a weak relationship was observed between occupation and district when knowledge of EVD preventive practices was considered.

\subsection{Attitudes about EVD}

Majority 94\% (803/852) of respondents acknowledged that EVD was a serious disease. 
Table 2. Distributions of knowledge tertiles for EVD symptoms by respondents' socio-demographic characteristics.

\begin{tabular}{|c|c|c|c|c|}
\hline \multirow{2}{*}{ Characteristic } & \multicolumn{4}{|c|}{ Tertiles } \\
\hline & Low & Medium & High & P-Value \\
\hline & n (\%) & n (\%) & n (\%) & \\
\hline \multicolumn{5}{|l|}{ Sex } \\
\hline Male & $120(35.3)$ & $108(31.8)$ & $112(32.9)$ & $\mathrm{P}=0.669$ \\
\hline Female & $196(38.3)$ & $153(29.9)$ & $163(31.8)$ & \\
\hline \multicolumn{5}{|l|}{ Age } \\
\hline$<20$ & $41(43.2)$ & $33(34.7)$ & $21(22.1)$ & $\mathrm{P}=0.215$ \\
\hline $20-29$ & $68(34.0)$ & $65(32.5)$ & $67(33.5)$ & \\
\hline $30-39$ & $79(34.6)$ & $63(27.6)$ & $86(37.7)$ & \\
\hline $40-49$ & $70(38.9)$ & $50(27.8)$ & $60(33.3)$ & \\
\hline $50+$ & $58(38.9)$ & $50(33.6)$ & $41(27.5)$ & \\
\hline \multicolumn{5}{|l|}{ Education } \\
\hline No Education & $124(45.6)$ & $80(29.4)$ & $68(25.0)$ & $\mathrm{P}<0.001$ \\
\hline Primary & $58(38.9)$ & $50(33.6)$ & $41(27.5)$ & \\
\hline Middle/JSS & $111(34.9)$ & $96(30.20)$ & 111 (34.)9 & \\
\hline Secondary & $23(20.4)$ & $35(31.0)$ & $55(48.7)$ & \\
\hline \multicolumn{5}{|l|}{ Occupations } \\
\hline Not Working & $55(48.7)$ & $47(36.7)$ & $36(28.1)$ & $\mathrm{P}=0.007$ \\
\hline Professional, Clerical & $8(22.2)$ & $4(11.1)$ & $24(66.7)$ & \\
\hline Self-employed trade & $52(35.1)$ & $46(31.1)$ & $50(33.8)$ & \\
\hline Other-employed trade & $11(27.50$ & $10(25.0)$ & $19(47.5)$ & \\
\hline Farmer, labourer, domestic & $180(40.4)$ & $135(30.3)$ & $130(29.2)$ & \\
\hline Student & $20(36.4)$ & $19(34.5)$ & $16(29.1)$ & \\
\hline \multicolumn{5}{|l|}{ Place of Residence } \\
\hline Small Rural & $47(30.9)$ & $70(46.1)$ & $35(23.0)$ & $\mathrm{P}<0.001$ \\
\hline Large Rural & $197(46.0)$ & $113(26.4)$ & $113(26.4)$ & \\
\hline Urban & $72(26.5)$ & $78(28.7)$ & $122(44.9)$ & \\
\hline \multicolumn{5}{|l|}{ Municipality/District } \\
\hline Kintampo North Municipality & $149(32.5)$ & $128(27.9)$ & $182(39.7)$ & $\mathrm{P}<0.000$ \\
\hline Kintampo South District & $167(42.5)$ & $133(33.8)$ & $93(23.7)$ & \\
\hline \multicolumn{5}{|l|}{ Household Wealth Quintile } \\
\hline Most Poor & $51(50.0)$ & $29(28.4)$ & $22(21.6)$ & $\mathrm{P}<0.001$ \\
\hline More Poor & $52(36.4)$ & $56(39.2)$ & $35(24.5)$ & \\
\hline Poor & $66(39.8)$ & $50(30.1)$ & $50(30.1)$ & \\
\hline Less Poor & $86(38.9)$ & $62(28.1)$ & $73(33.0)$ & \\
\hline Least Poor & $61(27.7)$ & $64(29.1)$ & $95(43.2)$ & \\
\hline
\end{tabular}


Table 3. Distributions of knowledge tertiles for modes of EVD transmission by respondents' socio-demographic characteristics.

\begin{tabular}{|c|c|c|c|c|}
\hline \multirow{2}{*}{ Characteristic } & \multicolumn{4}{|c|}{ Tertiles } \\
\hline & Low & Medium & High & P-Value \\
\hline & n (\%) & n (\%) & $\mathrm{n}(\%)$ & \\
\hline \multicolumn{5}{|l|}{ Sex } \\
\hline Male & $122(35.9)$ & $117(34.4)$ & $101(29.7)$ & $\mathrm{P}=0.953$ \\
\hline Female & $189(36.9)$ & $174(34.0)$ & $149(29.1)$ & \\
\hline \multicolumn{5}{|l|}{ Age } \\
\hline$<20$ & $35(36.8)$ & $29(30.5)$ & $31(32.6)$ & $\mathrm{P}=0.240$ \\
\hline $20-29$ & $66(33.0)$ & $71(35.5)$ & $63(31.5)$ & \\
\hline $30-39$ & $74(32.5)$ & $79(34.6)$ & $75(32.9)$ & \\
\hline $40-49$ & $71(39.4)$ & $59(32.8)$ & $50(27.8)$ & \\
\hline $50+$ & $65(43.6)$ & $53(35.6)$ & $31(20.8)$ & \\
\hline \multicolumn{5}{|l|}{ Education } \\
\hline No Education & $119(43.8)$ & $94(34.6)$ & $59(21.7)$ & $\mathrm{P}=0.001$ \\
\hline Primary & $53(35.6)$ & $56(37.6)$ & $40(26.8)$ & \\
\hline Middle/JSS & $112(35.2)$ & $104(32.7)$ & $102(32.1)$ & \\
\hline Secondary & 27 (23.9) & $37(32.7)$ & $49(43.4)$ & \\
\hline \multicolumn{5}{|l|}{ Occupations } \\
\hline Not Working & $44(34.4)$ & $50(39.1)$ & $34(26.6)$ & $\mathrm{P}=0.028$ \\
\hline Professional, Clerical & $10(27.8)$ & $9(25.0)$ & $17(47.2)$ & \\
\hline Self-employed trade & $42(28.4)$ & $51(34.5)$ & $55(37.2)$ & \\
\hline Other-employed trade & $14(35.0)$ & $15(37.5)$ & $11(27.5)$ & \\
\hline Farmer, labourer, domestic & $186(41.8)$ & $149(33.5)$ & $110(24.7)$ & \\
\hline Student & $15(27.3)$ & $17(30.9)$ & $23(41.8)$ & \\
\hline \multicolumn{5}{|l|}{ Place of Residence } \\
\hline Small Rural & $58(38.2)$ & $61(40.1)$ & $33(21.7)$ & $\mathrm{P}<0.001$ \\
\hline Large Rural & $180(42.1)$ & $138(32.2)$ & $110(25.7)$ & \\
\hline Urban & $73(26.8)$ & $92(33.8)$ & $107(39.3)$ & \\
\hline \multicolumn{5}{|l|}{ Municipality/District } \\
\hline Kintampo North Municipality & $128(27.9)$ & $162(35.3)$ & $169(36.8)$ & $\mathrm{P}<0.001$ \\
\hline Kintampo South District & $183(46.6)$ & $129(32.8)$ & $81(20.6)$ & \\
\hline \multicolumn{5}{|l|}{ Household Wealth Quintile } \\
\hline Most Poor & $43(42.2)$ & $22(21.6)$ & $37(36.3)$ & $\mathrm{P}=0.002$ \\
\hline More Poor & $57(39.9)$ & $56(39.2)$ & $30(21.0)$ & \\
\hline Poor & $67(40.4)$ & $67(40.4)$ & $44(26.5)$ & \\
\hline Less Poor & $85(38.5)$ & $78(35.3)$ & $58(26.2)$ & \\
\hline Least Poor & $59(26.8)$ & $80(36.4)$ & $81(36.8)$ & \\
\hline
\end{tabular}


Table 4. Percentage distributions of knowledge tertiles of EVD preventive practices by respondents' socio-demographic characteristics.

\begin{tabular}{|c|c|c|c|c|}
\hline \multirow{2}{*}{ Characteristic } & \multicolumn{4}{|c|}{ Tertiles } \\
\hline & Low & Medium & High & P-Value \\
\hline & n (\%) & n (\%) & n (\%) & \\
\hline \multicolumn{5}{|l|}{ Sex } \\
\hline Male & $120(35.3)$ & $131(38.5)$ & $89(26.2)$ & $\mathrm{P}=0.530$ \\
\hline Female & $171(33.4)$ & $217(42.4)$ & $124(24.2)$ & \\
\hline \multicolumn{5}{|l|}{ Age } \\
\hline$<20$ & $34(35.8)$ & $43(45.3)$ & $18(18.9)$ & $\mathrm{P}=0.610$ \\
\hline $20-29$ & $63(31.5)$ & $89(44.5)$ & $48(24.0)$ & \\
\hline $30-39$ & $74(32.5)$ & $92(40.4)$ & $62(27.2)$ & \\
\hline $40-49$ & $68(37.8)$ & $63(35.0)$ & $49(27.2)$ & \\
\hline $50+$ & $52(34.9)$ & $61(40.9)$ & $36(24.2)$ & \\
\hline \multicolumn{5}{|l|}{ Education } \\
\hline No Education & $128(47.1)$ & $98(36.0)$ & $46(16.9)$ & $\mathrm{P}<0.001$ \\
\hline Primary & $47(31.5)$ & $65(43.6)$ & $37(24.8)$ & \\
\hline Middle/JSS & $91(28.6)$ & $139(43.7)$ & $88(27.7)$ & \\
\hline Secondary & $25(22.1)$ & $46(40.7)$ & $42(37.2)$ & \\
\hline \multicolumn{5}{|l|}{ Occupations } \\
\hline Not Working & $47(36.7)$ & $58(45.3)$ & $23(18.0)$ & $\mathrm{P}=0.070$ \\
\hline Professional, Clerical & $4(11.1)$ & $18(50.0)$ & $14(38.9)$ & \\
\hline Self-employed trade & $46(31.1)$ & $63(42.6)$ & $39(26.4)$ & \\
\hline Other-employed trade & $9(22.5)$ & $17(42.5)$ & $14(35.0)$ & \\
\hline Farmer, labourer, domestic & $167(37.5)$ & $166(37.3)$ & $112(25.2)$ & \\
\hline Student & $18(32.7)$ & $26(47.3)$ & $11(20.0)$ & \\
\hline \multicolumn{5}{|l|}{ Place of Residence } \\
\hline Small Rural & $72(47.4)$ & $53(34.9)$ & $27(17.8)$ & $\mathrm{P}<0.001$ \\
\hline Large Rural & $151(35.3)$ & $165(38.6)$ & $112(26.2)$ & \\
\hline Urban & $68(25.0)$ & $130(47.8)$ & $74(27.2)$ & \\
\hline \multicolumn{5}{|l|}{ Municipality/District } \\
\hline Kintampo North Municipality & $151(32.9)$ & $190(41.4)$ & $118(25.7)$ & $P=0.693$ \\
\hline Kintampo South District & $140(35.6)$ & $158(40.2)$ & $95(24.2)$ & \\
\hline \multicolumn{5}{|l|}{ Household Wealth Quintile } \\
\hline Most Poor & $95(24.2)$ & $37(36.3)$ & $25(24.5)$ & $\mathrm{P}<0.001$ \\
\hline More Poor & $66(46.2)$ & $55(38.5)$ & $22(15.4)$ & \\
\hline Poor & $65(39.2)$ & $68(41.0)$ & $33(19.9)$ & \\
\hline Less Poor & $64(29.0)$ & $102(46.2)$ & $55(24.9)$ & \\
\hline Least Poor & $56(25.5)$ & $86(39.1)$ & $78(35.5)$ & \\
\hline
\end{tabular}


A smaller proportion 58\% (402/852) however saw themselves at risk of contracting the disease (Figure 4). A statement from an IDI seems to confirm the latter view: "The disease is not meant for one person. Everybody is liable. For example if there is an outbreak, I can contract it with my children." (Female, farmer)

Over $60 \%$ (528/852) of respondents did not agree that EVD affected only those who consumed bush meat or bats. Some IDI participants however had dissenting views: "...all animals in the bush have this disease so if you eat them or if you come into contact with these dead animals you can get it" (Male, chemical seller).

Close to $45 \%(380 / 852)$ of respondents did not agree that EVD was from curses or spirits, though 29.2\% (249/852) did. Respondents expressed divergent views in IDIs about the spiritual origin of the disease as below:

"Looking at it, it is obvious that it is caused by the devil...because these bats have been here for a long time. Have they now been seen as something which is not good enough for consumption? If it were not a devilish disease will that have been said? They (bats) are the only things in this community." (Male, farmer)

Our health facilities are equipped enough handle Ebola outbreaks

Not all people who gets Ebola die from it

It is not possible to prevent the spread of Ebola

I am at risk contracting Ebola

Elola is curable through medical treatment

Ebola is curable through spiritual treatment and prayers

Ebola is a serious disease

Ebola is a disease for only people who eat bush meat or bats

Eblola is a curse or spiritual disease Ebola is a combination of all serious diseases in the world

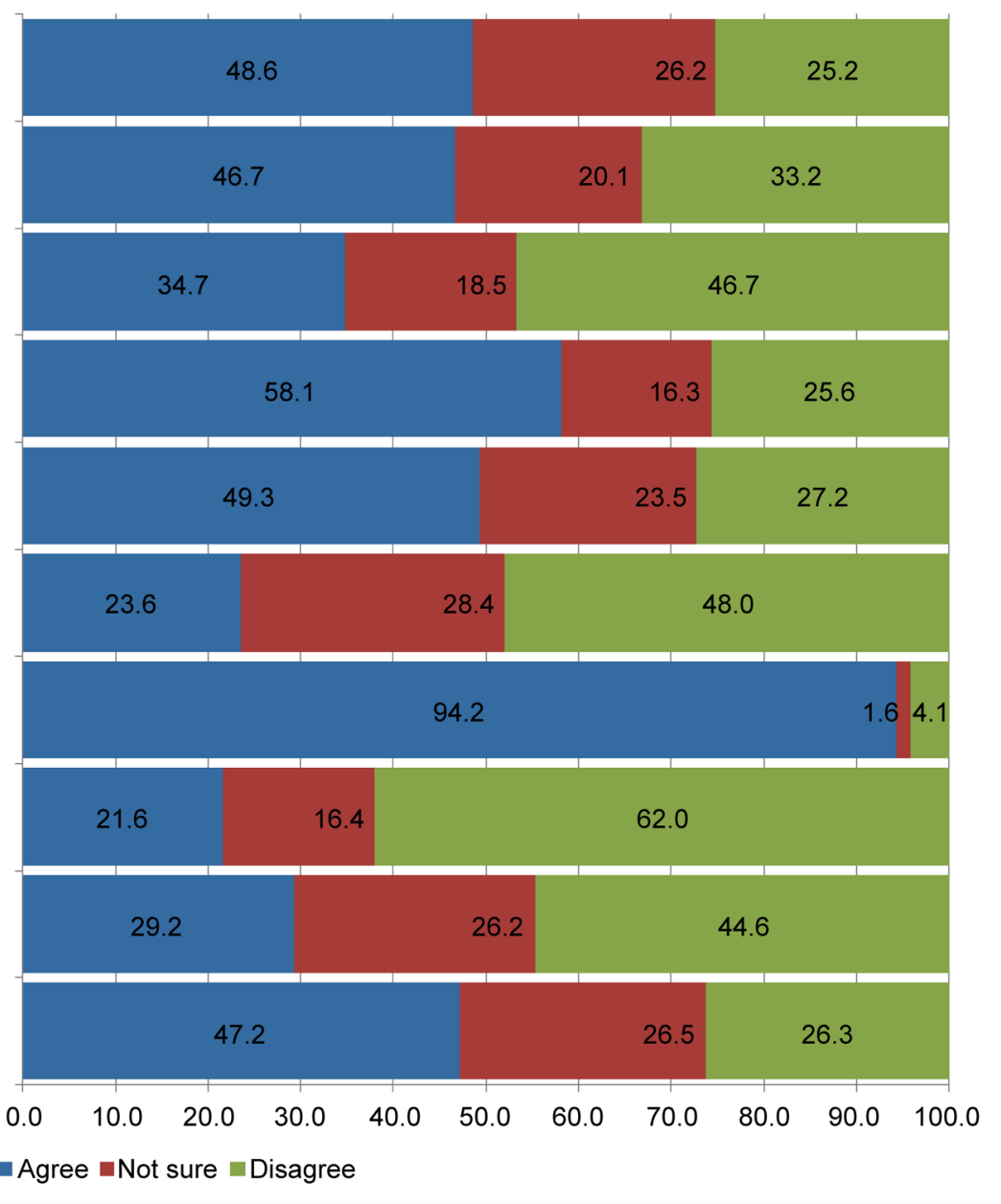

Figure 4. Attitudes about EVD. 
"If they say it a spiritual disease or it is a curse, I don't think so, how can it be a curse, so can we say that all Ghanaians have been cursed or what? It is not a curse, I don't think so." (Female, farmer)

"All we can do is to pray. We are all praying that this disease shouldn't come here [in Ghana]." (Female, farmer)

A little over $49 \%$ (420/852) of respondents viewed EVD as curable through medical treatment. Similar proportions, $46.7 \%$ (398/852) agreed that not all infected with EVD die from it.

The varied views on the cure for EVD from IDIs are as follows:

"I hear the Government has found a medicine for the disease. That is what I heard on the radio. They said we shouldn't get worried because there is going to be a cure. I don't know if it is true or false..." (Female, farmer)

"There is no cure at the moment." (Male, farmer)

Forty-seven percent (398/852) of respondents thought it was feasible to prevent EVD. Also $48.6 \%$ (414/852) of respondents believed health facilities in the country were well-equipped to handle EVD outbreaks (Figure 4).

Some views on containing the outbreak were elicited during an IDI:

“I don't think they are prepared, I have never heard that this is what we the smaller facilities will use to protect ourselves when there is an outbreak" (Male, chief).

\subsection{Respondents' First Action on Suspicion of a Case of EVD}

Upon suspecting a case of EVD 35.1\% (299/852) of respondents would first take the sick person to the health facility immediately, 11\% (95/852) would leave the premises of the suspected case without any further action, and 6\% (51/852) would inform health professionals to immediately quarantine the premises. Less than $1 \%$ each $(5 / 852)$ of respondents would first send patients for prayers or herbal/spiritual treatment, or $(4 / 852)$ buy drugs for them, or $(4 / 852)$ call a radio station or other media outlets or (1/852) give oral rehydration salts.

\subsection{Respondents' Current Actions in EVD Prevention}

At the time of the survey, respondents took the following actions to prevent EVD: $83 \%$ (704/852) improved hand hygiene, 81\% (686/852) avoided shaking hands or having physical contact with people, $80 \%$, (677/852) kept their surroundings clean, 71\% (602/ $852)$ reduced or stopped bush meat or pork consumption, and 52\% (440/852) avoided close contact with sick people or animals.

\section{Discussion}

This study sought to describe knowledge, attitudes and preventive practices concerning EVD in the Kintampo districts, located in the middle belt of Ghana. This is essential to developing preventive interventions for community members considering that there is free movement of persons across the West African sub-region. We observed a high lev- 
el of awareness of EVD. In the study area-over $80 \%$ of respondents had heard of EVD. In countries like Sierra Leone, awareness at the height of the outbreak was 100\% [14]. Gaps however were observed in respondents' knowledge and attitudes towards EVD that were likely to impact on behaviours and preventive practices. This is evidenced from survey results where almost half of the respondents were ignorant about the fact that the disease had no cure and were not aware of how long it took for symptoms of EVD to manifest.

\subsection{Source of Information about EVD}

Public education is fundamental to strategies aimed at controlling an EVD outbreak. Radio was the commonest source of EVD information in our studied area, similar to observations in a study in Sierra Leone [14]. Being the most accessible media source for much of sub-Saharan Africa [15], it should continue to be recognized as a dominant medium of propagating important information to rural populations such as the study communities. Television, social networks of friends and relations, churches, mosques and shrines could serve as complimentary media in integrating public education strategies.

\subsection{Knowledge of EVD}

Knowledge gaps were observed in this study. Knowledge of signs and symptoms, modes of transmission and prevention of EVD varied across the socioeconomic strata of respondents. Clearly, people with no education, those not working, most poor, those living in small rural communities were also the least knowledgeable in EVD, placing them at risk of contracting and spreading the disease. EVD communication strategies should aim at educating these groups on the various aspects of the disease.

Bleeding from body orifices was the most well-known symptom. This is primarily due to the pre-eminence of this symptom given by most messages in the study area. The focus on bleeding, however, is problematic, as though it occurs rapidly, it does not occur at onset of the disease [16] and is also rare [17]. Educational messages should emphasize on early general symptoms such as headache, rashes, intense weakness, sore throat, muscle pain, sunken eyes, abdominal pain, reduced urine output, difficulty in breathing and chest pain. This is especially important in areas where malaria, which presents with similar symptoms, is common. Public education on the early symptoms of EVD is even more important now, considering the fact that the current EVD strain is not of the haemorrhagic type [18].

Respondents mentioned handshake/skin contact with EVD cases, eating bats, monkeys and other bush-meat as the most widely known modes of transmission. This is not surprising as existing messages have focused on such issues. There were however uncertainties about body fluids' role in EVD transmission. The levels of ignorance are quite worrying, as direct contact with body fluids of EVD patients or living in contaminated environments greatly increases the risk of being infected [19]. Knowledge of urine and faeces as modes of transmission was low, especially as disposal is poor and individuals easily come into contact with such waste. Also, EVD can also persist in body 
fluids like semen after clinical recovery [20].

Also, cultural practices involving handling the dead, as in much of Ghana [21], are widespread in the study area. It is important, therefore, that such knowledge gaps should be targeted to ensure that the population, in case of an outbreak, does not facilitate the spread of infections. The role of body fluids and the possibility of transmission through sexual intercourse should also be highlighted.

On prevention of EVD, respondents demonstrated an appreciable level of knowledge. This is encouraging as one would have expected a lower level of knowledge in a population not currently experiencing an outbreak. Over the months ahead of this study, several activities had been organized to improve EVD awareness and preparedness in Ghana. For instance, EVD issues gained prominence on the media. A number of workshops and training were also organized for health and other key staff such as border officials. The appreciable high level of prevention knowledge could be fairly attributed to such interventions.

Some EVD prevention approaches were however better known. Reducing contact with bats, monkeys, pigs and other wild animals was the best known, followed by maintaining good hand hygiene. This level of knowledge is positive in light of the fact that the study area has a bush-meat consuming population.

\subsection{Attitudes toward EVD}

Study results suggest a higher sense of risk perception. Majority of respondents agree that EVD is a serious disease and that they are at risk of contracting it. They also disagree that EVD is a disease for only people who eat bush-meat or bats.

Respondents' understanding as to whether a person with EVD could be cured was mixed. Generally, the discourse surrounding EVD highlights its virulence with messages of possible survival being rather vague. For instance, less than half of respondents agree that not all people infected with EVD die from it. A similar proportion agree that EVD is curable through medical treatment or that our health facilities are equipped enough to handle outbreaks. It is important that subsequent messages highlight the point that one contracting EVD does not necessarily lead to death and that with early reporting, recovery is possible. This message will also help reduce stigmatization of entire families that are suspected to have cases.

Another major theme that was explored in the current study was people's perceptions of the linkages between spirituality and EVD infection. Findings showed a mixed picture as over a quarter of respondents agreed that EVD was a curse or spiritual disease and was curable through spiritual treatment and prayers (Figure 4). A fifth (20\%) of respondents in a 2014 Sierra Leonean study [14] perceived the condition as spiritual. A further quarter of respondents in the current study were not certain if EVD was a curse or curable spiritually (Figure 4).

\subsection{Limitations}

The responses to questions that required an interviewer's prompt may have been over- 
estimated. This is because respondents could possibly have guessed answers, when they actually were unaware of it. Field staffs were trained to further probe during the survey to ascertain that respondents truly provided answers they were certain about. As surveys were conducted during the day, males and 15 - 19 year-olds were under-represented (by $8.7 \%$ and $9.5 \%$ respectively) mainly because they were not met in their homes as they were at work or at school. Further analysis by the authors shows that households selected were however, largely representative of the population. As shown in this study, differences in knowledge by sex and age were not statistically significant. Thus, this under-sampling is not expected to significantly affect findings. Also, this paper did not explore the impact of the source of information on the quality of the message. This will be the subject of another manuscript.

\section{Conclusion}

This study has documented high levels of awareness of EVD in the Kintampo districts. Some important gaps were also identified in knowledge of symptoms and mode of transmission of EVD. There was a high level of ignorance concerning body fluids as modes of transmission. Radio was the commonest means by which respondents heard about EVD. Community members agreed to EVD being a serious disease and that they were at risk of contracting it. The awareness of preventive approaches was also high among household respondents. There was, however, some uncertainty about the curable nature of EVD through medical treatment. There is the need to not only intensify but to improve the quality of educational messages as part of interventions to prepare Ghana for a potential EVD outbreak.

\section{Acknowledgements}

The authors wish to thank the Ghana Health Service, Municipal and District Assemblies, chiefs, elders, opinion leaders and community members in the study area for their goodwill and continual interest in participating in KHRC's activities; staff of KHRC, especially the KHDSS staff. KHRC is a member-centre of the INDEPTH Network.

\section{Competing Interests}

The authors declare that they have no competing interests. Funding for this study was provided by the KHRC Research Fund.

\section{Authors' Contributions}

Original idea: OEAN; Conceptualization and questionnaire design: All authors; Data collection: OEAN, CZ, EAA, MA, FA and AQD; Data analysis: OEAN, YAE, CZ, EAA, MA, FA, MT, DA, LGF, KAA, KPA and SO; Critical review and comments: All authors; Initial drafts: OEAN; All authors read and approved the final manuscript

\section{References}

[1] World Health Organization (2016) Ebola Situation Report. 30th March 2016. 
[2] Tomori, O. (2014) Ebola in an Unprepared Africa. BMJ, 349, 5597. http://dx.doi.org/10.1136/bmj.g5597

[3] The Kaiser Family Foundation. Ebola Outbreak Having Devastating Effects on HCWs, Health Systems in West Africa.

[4] Acharya, M. (2014) Ebola Viral Disease Outbreak-2014: Implications and Pitfalls. Frontiers in Public Health, 2, 263. http://dx.doi.org/10.3389/fpubh.2014.00263

[5] Gomes, M.F., Pastore y Piontti, A., Rossi, L., Chao, D., Longini, I., Halloran, M.E. and Vespignani, A. (2014) Assessing the International Spreading Risk Associated with the 2014 West African Ebola Outbreak. PLoS Currents Outbreaks, 1, 1-23

[6] UNDP (2014) Socio-Economic Impact of the Ebola Virus Disease in Guinea, Liberia and Sierra Leone. Policy Notes, Vol. 1, No. 1-5.

[7] Cooper, H. (2014) Ebola's Cultural Casualty: Hugs in Hands-On Liberia. The New York Times, 04-Oct-2014.

[8] Ayenigbara, G.O. (2014) The Facts, the Fears, and the Prevention of Ebola Haemorrhagic Fever: A Focus on Nigeria. .

[9] World Health Organization (2014) WHO Factsheet on Ebola Virus Disease. WHO, Sep2014. http://www.who.int/mediacentre/factsheets/fs103/en/

[10] Owusu-Agyei, S., Nettey, O.E.A., Zandoh, C., Sulemana, A., Adda, R., Amenga-Etego, R. and Mbacke, C. (2012) Demographic Patterns and Trends in Central Ghana: Baseline Indicators from the Kintampo Health and Demographic Surveillance System. Global Health Action, 5, 19033. http://dx.doi.org/10.3402/gha.v5i0.19033

[11] Nettey, O.E.A., Zandoh, C., Sulemana, A., Adda, R. and Owusu-Agyei, S. (2010) Clustering of Childhood Mortality in the Kintampo Health and Demographic Surveillance System in Ghana. Global Health Action, 3. http://dx.doi.org/10.3402/gha.v3i0.5258

[12] Kunii, O., Formenty, P., Diarra-Nama, J. and Nahounou, N. (1999) Risk for Ebola Virus Infection in Côte d'Ivoire. Emerging Infectious Diseases, 5, 312-313. http://dx.doi.org/10.3201/eid0502.990232

[13] StataCorp (2011) Stata Statistical Software: Release 12. College Station, TX: StataCorp LP.

[14] Catholic Relief Services, Focus 1000, and United Nations International Children Emergency Fund (UNICEF) (2014) Study on Public Knowledge, Attitudes, and Practices Related to EVD Prevention and Medical Care in Sierra Leone. http://www.mamaye.org.sl/sites/default/files/KAP\%20Summary_Sept302014.pdf

[15] Myers, M. (2011) Voices from Villages. Community Radio in the Developing World. A Report to the Center for International Media Assistance, CIMA, Washington DC.

[16] Feldmann, H. and Geisbert, T.W. (2011) Ebola Haemorrhagic Fever. The Lancet, 377, 849862. http://dx.doi.org/10.1016/S0140-6736(10)60667-8

[17] Schieffelin, J.S., Shaffer, J.G., Goba, A., Gbakie, M., Gire, S.K., Colubri, A., Sealfon, R.S.G., Kanneh, L., Moigboi, A., Momoh, M., Fullah, M., Moses, L.M., Brown, B.L., Andersen, K.G., Winnicki, S., Schaffner, S.F., Park, D.J., Yozwiak, N.L., Jiang, P.-P., Kargbo, D., Jalloh, S., Fonnie, M., Sinnah, V., French, I., Kovoma, A., Kamara, F.K., Tucker, V., Konuwa, E., Sellu, J., Mustapha, I., Foday, M., Yillah, M., Kanneh, F., Saffa, S., Massally, J.L.B., Boisen, M.L., Branco, L.M., Vandi, M.A., Grant, D.S., Happi, C.,. Gevao, S.M., Fletcher, T.E., Fowler, R.A., Bausch, D.G., Sabeti, P.C., Khan, S.H. and Garry, R.F. (2014) Clinical Illness and Outcomes in Patients with Ebola in Sierra Leone. The New England Journal of Medicine, 371, 2092-2100. http://dx.doi.org/10.1056/NEJMoa1411680

[18] Bray, M., Hirsch, M.S., Mitty, J. and Chertow, D.S. (2015) Clinical Manifestations and Diagnosis of Ebola Virus Disease. 
[19] Liu, W.B., Li, Z.X., Du, Y. and Cao, G.W. (2015) Ebola Virus Disease: From Epidemiology to Prophylaxis. Military Medical Research, 2, 7.

[20] Chugtai, A.A., Barnes, M. and MacIntyre, C.R. (2016) Persistence of Ebola Virus in Various Body Fluids during Convalescence: Evidence and Implications for Disease Transmission and Control. Epidemiology and Infection, 144, 1652-1660.

http://dx.doi.org/10.1017/S0950268816000054

[21] van der Geest, S. (2006) Between Death and Funeral: Mortuaries and the Exploitation of Liminality in Kwahu, Ghana. Africa, 76, 485-501. http://dx.doi.org/10.3366/afr.2006.0061

\section{Abbreviations}

EVD: Ebola Virus Disease; WHO: World Health Organization; KHRC: Kintampo Health Research Centre; KHDSS: Kintampo Health and Demographic Surveillance System; IDI: In-depth Interview; KAP: Knowledge, Attitude and Practice

Submit or recommend next manuscript to SCIRP and we will provide best service for you:

Accepting pre-submission inquiries through Email, Facebook, LinkedIn, Twitter, etc. A wide selection of journals (inclusive of 9 subjects, more than 200 journals)

Providing 24-hour high-quality service User-friendly online submission system

Fair and swift peer-review system

Efficient typesetting and proofreading procedure

Display of the result of downloads and visits, as well as the number of cited articles Maximum dissemination of your research work

Submit your manuscript at: http://papersubmission.scirp.org/

Or contact health@scirp.org 